\title{
Comparison of Conventional Cyclophosphamide versus Fludarabine-Based Conditioning in High-Risk Aplastic Anemia Patients Undergoing Matched-Related Donor Transplantation
}

\author{
Raheel Iftikhar ${ }^{1, *(\mathbb{D})}$, Qamar un Nisa Chaudhry ${ }^{1}$, Tariq Mehmood Satti ${ }^{1}$, Syed Kamran Mahmood ${ }^{1}$, Tariq Ghafoor ${ }^{10}$, \\ Ghassan Umair Shamshad $^{1}$, Nighat Shahbaz ${ }^{10}$, Mehreen Ali Khan ${ }^{1}$, Tariq Azam Khattak ${ }^{1}$, Jahanzeb Rehman ${ }^{1}$, \\ Muhammad Farhan ${ }^{1}$, Saima Humayun ${ }^{1}$, Humera Haq ${ }^{1}$, Syeda Ammaara Anwaar Naqvi ${ }^{1}$, Faiz Anwer ${ }^{2}$, \\ Humayoon Shafique Satti ${ }^{3}$, Parvez Ahmed ${ }^{4}$
}

${ }^{1}$ Department of Hematology and Stem Cell Transplant, Armed Forces Bone Marrow Transplant Center/National Institute of Blood and Marrow Transplant, Rawalpindi 46000, Pakistan

${ }^{2}$ Department of Hematology, Medical Oncology, Taussig Cancer Center, Cleveland Clinic, Cleveland, OH 44195, USA

${ }^{3}$ National University of Medical Sciences, Rawalpindi 46000, Pakistan

${ }^{4}$ Department of Hematology-Oncology and Stem Cell Transplant, Quaid-e-Azam International Hospital, Islamabad 44000, Pakistan

\section{ARTICLE INFO}

Article History

Received 16 Dec 2019

Accepted 24 Apr 2020

Keywords

Aplastic anemia

Cyclophosphamide

Fludarabine

Stem cell transplantation

\begin{abstract}
Allogeneic stem cell transplant for high-risk aplastic anemia (AA) yields inferior results using conventional cyclophosphamide (CY)-based conditioning. The use of fludarabine (Flu)-based regimens has resulted in improved outcomes in high-risk patients. Limited data are available comparing these two conditioning regimens in such patients. We retrospectively analyzed 192 highrisk patients undergoing matched-related donor transplantation from July 2001 to December 2018 . The median age was 19.5 (2-52) years. Patients were divided into 2 groups, $\mathrm{Cy}^{200}$ anti-thymocyte globulin $(\mathrm{ATG})^{20}\left(\mathrm{Gp} 1 \mathrm{n}=79\right.$ ) or Flu ${ }^{120-150} \mathrm{Cy}^{120-160}$ $\mathrm{ATG}^{20}(\mathrm{Gp} 2 \mathrm{n}=113)$. The risk of graft failure was significantly higher in $\mathrm{Gp} 1$, and the majority occurred in patients with $>2$ risk factors $(p=0.02)$. The incidence of grade II-IV acute graft versus host disease (GVHD) and chronic GVHD was not significantly different between the two groups. The overall survival (OS) of the study cohort was $81.3 \%$, disease-free survival (DFS) $76.6 \%$ and GVHD-free relapse-free survival (GRFS) was 64.1\%. DFS and GRFS were significantly higher in Gp2 as compared to Gp1: DFS $84.1 \%$ versus $68.4 \%(p=0.02)$, GRFS $77.9 \%$ versus $54.4 \%(p=0.01)$, respectively. We conclude that Flu-based conditioning is associated with superior OS, DFS and GRFS as compared to the conventional Cy-based regimen in high-risk AA.
\end{abstract}

(C) 2020 International Academy for Clinical Hematology. Publishing services by Atlantis Press International B.V. This is an open access article distributed under the CC BY-NC 4.0 license (http://creativecommons.org/licenses/by-nc/4.0/).

\section{INTRODUCTION}

Allogeneic hematopoietic stem cell transplant (HSCT) is the standard treatment for patients younger than 40 years with severe and very severe aplastic anemia (AA) who have a matched-related donor (MRD) [1]. A combination of cyclophosphamide (CY) at $200 \mathrm{mg} / \mathrm{kg}$ plus rabbit anti-thymocyte globulin (ATG) conditioning regimen, cyclosporine and methotrexate (MTX) for graft-versus host disease (GVHD) prophylaxis and bone marrow harvest $(\mathrm{BMH})$ as stem cell source is considered preferable in MRD transplants [2]. Different studies have shown that increasing age, heavy pretransplant transfusion burden and prolonged disease duration before transplant are associated with inferior outcomes in AA patients $[3,4]$.

${ }^{*}$ Corresponding author. Postal address: Armed Forces Bone Marrow Transplant Center, Rawalpindi, Pakistan 46000. Tel.: 03335171505.Email: drraheeliftikhar@gmail.com Peer review under responsibility of the International Academy for Clinical Hematology Data availability statement: The datasets of current study are available from the corresponding author on email request.
In developing countries like Pakistan, the majority of patients have one or more of these risk factors at the time of transplant, and are thus considered high risk for graft failure (GF), GVHD and infectious complications posttransplant. Our institutional experience and different studies across the globe have suggested that fludarabine (FLU)-based conditioning regimens reduce GF, improve engraftment, reduce regimen-related toxicities and improve overall survival (OS) in these high-risk patients [5-8]. We recently published our single center experience using different FLU-based conditioning, and documented the efficacy of the different regimens used [8]. Despite favorable results with FLU-based conditioning $[9,10]$, there is still no consensus on optimal regimen for these high-risk AA patients, and CY-ATG is still considered the standard of care for AA patients without giving due consideration to the presence of high-risk features. The purpose of this retrospective analysis is to compare the outcome of the two most frequently used regimens, CY-ATG versus FLU-CY-ATG, to identify the preferable conditioning regimen for high-risk AA patients. 


\section{MATERIALS AND METHODS}

We retrospectively analyzed data from 241 AA patients who received MRD transplant using either conventional CY at 200 $\mathrm{mg} / \mathrm{kg}$ and ATG at $20 \mathrm{mg} / \mathrm{kg}$ or FLU at $120-150 \mathrm{mg} / \mathrm{m}^{2}, \mathrm{CY}$ at $120-$ $160 \mathrm{mg} / \mathrm{kg}$ and ATG at $20 \mathrm{mg} / \mathrm{kg}$ conditioning at the Armed Forces Bone Marrow Transplant Center/National Institute of Blood and Marrow Transplant (AFBMTC/NIBMT) from July 2001 to December 2018. Twenty-seven patients did not have any high-risk features and were excluded from the study. We identified 22 patients who had active infection at the time of transplantation and were taken to transplant as only available salvage therapy; these were also excluded from the study. Data analysis was done on 192 patients fulfilling the study inclusion and exclusion criteria. AA was defined as pancytopenia and hypocellular bone marrow in the absence of abnormal infiltrate or bone marrow fibrosis. We used Camitta et al.s [11], and Bacigalupo et al's [12] criteria for grading the severity of AA. As per the AFBMTC/NIBMT defined criteria, patients were considered as high risk if they had 1 or more of the following features: Age $\geq 20$ year, previous HSCT, time from diagnosis to transplant $>3$ months, $>20$ red cell transfusions or $>50$ platelet transfusions [8]. This score is currently being validated using a prospective trial at our center.

DNA-based low/intermediate resolution typing was done for HLAclass I and class II antigen matching. Recipients received grafts from 6/6 HLA-matched sibling or family donors (185 siblings, 6 parents, 1 nephew).

The inclusion criteria were high-risk AA patients receiving MRD HSCT with either conventional $\mathrm{CY}^{200} \mathrm{ATG}^{20}$ or Flu ${ }^{120-150} \mathrm{CY}^{120-160}$ $\mathrm{ATG}^{20}$ ) conditioning; age $>2$ years, absence of severe infection at the time of transplant; ejection fraction $>50 \%$; serum creatinine $<130$ $\mu \mathrm{mol} / \mathrm{L}$; serum bilirubin $<34 \mu \mathrm{mol} / \mathrm{L}$; pulmonary functions $>70 \%$ of predicted and informed written consent for recipient and donor. Exclusion criteria included high hematopoietic cell transplantationcomorbidity index (HCT-CI), paroxysmal nocturnal hemoglobinuria $(\mathrm{PNH})$ clone with clinical evidence of hemolysis, presence of somatic abnormalities reflective of constitutional bone marrow failure [13], positive cytogenetic studies for chromosomal breakage, pregnancy, Karnofsky score $<70 \%$ and patients lost to follow up. The study was approved by the Institute's Ethical Review Board and Research Department.

\subsection{Transplantation and Supportive Care}

The AFBMTC/NIBMT is the only purpose-built Transplant center of Pakistan, currently carrying out around 100 allogeneic HSCT per year. It complies with international guidelines on the protective environment for HSCT published in 2009 [14]. Patients were admitted to isolation rooms with laminar airflow and HEPA filters. Antiviral, antifungal, and Pneumocystis jirovecii (PJP) prophylaxis were administered to all transplant recipients. We used a preemptive strategy for cytomegalovirus (CMV) treatment: ganciclovir/valganciclovir was given if $>2,000 \mathrm{CMV}$ copies were detected, and continued until 2 consecutive PCR results were negative.

AA is the leading transplant indication at our center since 2001 [15]. Patients receiving conventional CY-ATG conditioning were labeled as group Gp1 and those receiving FLU-CY-ATG were labeled as
Gp2. Stem cell sources included BMH alone, BMH combined with peripheral blood stem cell (PBSC) and PBSC alone. PBSC alone was used due to donor choice, major $\mathrm{ABO}$ mismatch, and disparity of age and weight between donor and recipient.

Cyclosporine alone and cyclosporine plus a short course of MTX $\left(10 \mathrm{mg} / \mathrm{m}^{2}\right.$ on day $+1,8 \mathrm{mg} / \mathrm{m}^{2}$ on day +4 and day +7$)$ were used as GVHD prophylaxis. Whole blood and lineage-specific chimerism were used for posttransplant monitoring on days $+28,+100$ and +180 , or as needed per clinical indication, e.g. drop in blood counts.

Neutrophil engraftment was defined as the first of three consecutive days with ANC $>0.5 \times 10^{9} / \mathrm{L}$ and platelet engraftment as unsupported platelet count $>20 \times 10^{9} / \mathrm{L}$ for seven days. Primary graft failure (PGF) was defined as the failure to achieve neutrophil engraftment by day +28 and secondary GF as persistent neutropenia $\left(\right.$ ANC $\left.<0.5 \times 10^{9} / \mathrm{L}\right)$ after initial engraftment. Acute GVHD (aGVHD) was diagnosed by the presence of skin rash, loose stools and jaundice early posttransplant $(<100$ days), confirmed with or without biopsy and graded according to the Glucksberg criteria [16]. Chronic GVHD (cGVHD), clinically diagnosed as per NIH criteria, was divided into limited and extensive disease [17]. The primary endpoint was OS. Secondary endpoints were day-100 transplant-related mortality (TRM), disease-free survival (DFS), GVHD-free relapse-free survival (GRFS), aGVHD, cGVHD and infectious complications. TRM was defined as death within 100 days due to any transplant-related cause other than disease relapse. OS was defined as the time from HSCT to death from any cause. DFS was calculated as survival in the absence of rejection, and GRFS included patients who were alive, free of GVHD and disease relapse on the last evaluation.

\section{STATISTICAL ANALYSIS}

Kaplan-Meier survival curves were used to estimate OS, DFS and GRFS. Patients were censored at the time of last follow-up and differences in survival were compared using the log rank test. We used univariate and multivariate Cox regression analysis to determine the significance of different variables as per conditioning regimen used, and their effect on survival. The chi-square test was used to compare transplant and patient-related categorical variables between conditioning regimens, while a Student's t-test or a MannWhitney U-test was used for continuous variables. The Fisher's exact test was used to confirm chi-square results when less than 5 observations were present in any group. We considered a $p=0.05$ or less to be significant, and used SPSS version 23.0 (IBM; NY; USA) to complete our statistical analysis.

\section{RESULTS}

\subsection{Patient Characteristics}

As per inclusion and exclusion criteria, we identified 192 patients who had received either $\mathrm{Cy}^{200} \mathrm{ATG}^{20}(\mathrm{Gp} 1 \mathrm{n}=79)$ or Flu ${ }^{120-150}$ $\mathrm{Cy}^{120-160} \mathrm{ATG}^{20}(\mathrm{Gp} 2 \mathrm{n}=113)$ conditioning. The median age was 19.5 years (range $2-52$ years). None of the patients $>40$ years received HSCT in Gp1 while 3 were transplanted in Gp2. The study cohort included 150 males and 42 females (3.5:1). 
The median time from diagnosis to transplantation was 10 months and it ranged from 1.5 to 132 months. Nine patients (4.6\%) received immunosuppression pre-HSCT. Cytogenetic records were available for 164 patients. Cytogenetic abnormalities were detected in only 4. These included trisomy 8 in 2 patients, del13q in 1 and del20q in 1 . Two patients (1\%) received rabbit ATG and cyclosporine, and seven (3.6\%) received cyclosporine alone. None of the patients had a hematologic response to immunosuppression. Four patients (2\%) received second HSCT for secondary GF. Three of these four had received CY at $200 \mathrm{mg} / \mathrm{kg}$ and ATG-F $20 \mathrm{mg} / \mathrm{kg}$ as first conditioning regimen, while 1 had initially received FLU at $150 \mathrm{mg} / \mathrm{m}^{2}$; CY at 300 $\mathrm{mg} / \mathrm{m}^{2}$ and ATG at $20 \mathrm{mg} / \mathrm{kg}$. A PNH clone was present in $14.6 \%$ of the cohort, but was clinically insignificant, without hemolysis, in all patients. Comparison of demographic characteristics of the study population as per conditioning regimen showed that patients in the Gp2 (FLU-based conditioning) were older ( $p=0.01$ ), had longer duration of disease from diagnosis to transplant $(p=0.024)$, received more red cell and platelet transfusions $(p=0.001$ and $<0.001$, respectively). This group included all four patients who had failed previous HSCT (Figure 1). Patients' characteristics according to the type of conditioning regimen used are summarized in Table 1.

\subsection{Transplant Characteristics and Engraftment}

We started using FLU-based conditioning at our center in 2004, and then increased its use after encouraging results. Our experience of FLU with reduced dose CY $\left(300 \mathrm{mg} / \mathrm{m}^{2}\right)$ showed inferior results, due to a higher frequency of primary and secondary GF [8], so this regimen is no longer used for high-risk patients at our center. We used $\mathrm{BMH}$ alone as a stem cell source in 97 patients (50.5\%), combined $\mathrm{BMH}$ and PBSC harvest in 82 (42.7\%) and PBSC alone in

Table $1 \mid$ Demographic characteristics of study population.

\begin{tabular}{|c|c|c|c|c|}
\hline \multirow[t]{2}{*}{ Ser No } & \multirow[t]{2}{*}{ Patient Characteristics } & \multicolumn{2}{|c|}{ Conditioning Regimen } & \multirow[t]{2}{*}{$p$} \\
\hline & & $\mathrm{Gp} 1^{\mathrm{a}}$ & $\mathrm{Gp} 2^{\mathrm{a}}$ & \\
\hline 1. & Number of patients (n) & 79 & 113 & 0.44 \\
\hline 2. & Gender male: female & $2.4: 1$ & 4.9:1 & 0.05 \\
\hline 3. & $\begin{array}{l}\text { Age years median } \\
\text { (range) }\end{array}$ & $16(2-38)$ & $21(3-52)$ & 0.01 \\
\hline \multirow[t]{6}{*}{4.} & Age groups n(\%) & & & 0.01 \\
\hline & $>2-10$ years & $19(24)$ & $11(9.7)$ & \\
\hline & $11-20$ years & $34(43.2)$ & $43(38.3)$ & \\
\hline & $21-30$ years & $19(24)$ & $48(42.4)$ & \\
\hline & $31-40$ years & $7(8.8)$ & $8(7)$ & \\
\hline & $>40$ years & & $3(2.6)$ & \\
\hline 5. & Prior ATG n(\%) & $1(50)$ & $1(50 \%)$ & - \\
\hline 6. & Prior cyclosporine & $4(57.1)$ & $3(42.9)$ & 0.52 \\
\hline 7. & $\begin{array}{l}\text { Time from diagnosis to } \\
\text { transplant months, } \\
\text { (range) }\end{array}$ & $6(1.5-76)$ & $13(2-132)$ & 0.024 \\
\hline 8. & $\begin{array}{l}\text { PNH clone ( } 41 \\
\text { evaluable cases n }(\%)\end{array}$ & - & $6(14.6)$ & 0.392 \\
\hline 9. & Previous HSCT; n (\%) & - & $4(3.5)$ & 0.145 \\
\hline 10. & $\begin{array}{l}\text { Serum ferritin ng/mL; } \\
\text { median (range) }\end{array}$ & $\begin{array}{c}1015 \\
(169-3161)\end{array}$ & $\begin{array}{c}2840 \\
(63-5400)\end{array}$ & 0.042 \\
\hline 11. & $\begin{array}{l}\text { RCC transfused; } \\
\text { median (range) }\end{array}$ & $20(2-120)$ & $38(1-200)$ & 0.001 \\
\hline 12. & $\begin{array}{l}\text { Platelets transfused; } \\
\text { median (range) }\end{array}$ & $50(3-400)$ & $\begin{array}{c}111 \\
(13-400)\end{array}$ & $<0.001$ \\
\hline 13. & $\begin{array}{l}\text { Donor age; years } \\
\text { (median: range) }\end{array}$ & $17(3-45)$ & $22(2-50)$ & 0.361 \\
\hline
\end{tabular}

(a) Gp1 and Gp2 denotes patients receiving $\mathrm{Cy}^{200} / \mathrm{ATG}^{20}$ and $\mathrm{Flu}^{120-150} \mathrm{Cy}^{120} \mathrm{ATG}^{20}$ respectively.

$\mathrm{N}$ : number; PNH: paroxysmal nocturnal hemoglobinuria; HSCT: hematopoietic stem cell transplant; RCC: red cell concentrate; NSAA: nonsevere aplastic anemia; SAA: severe aplastic anemia; VSAA: very severe aplastic anemia; UPN: unique patient number.

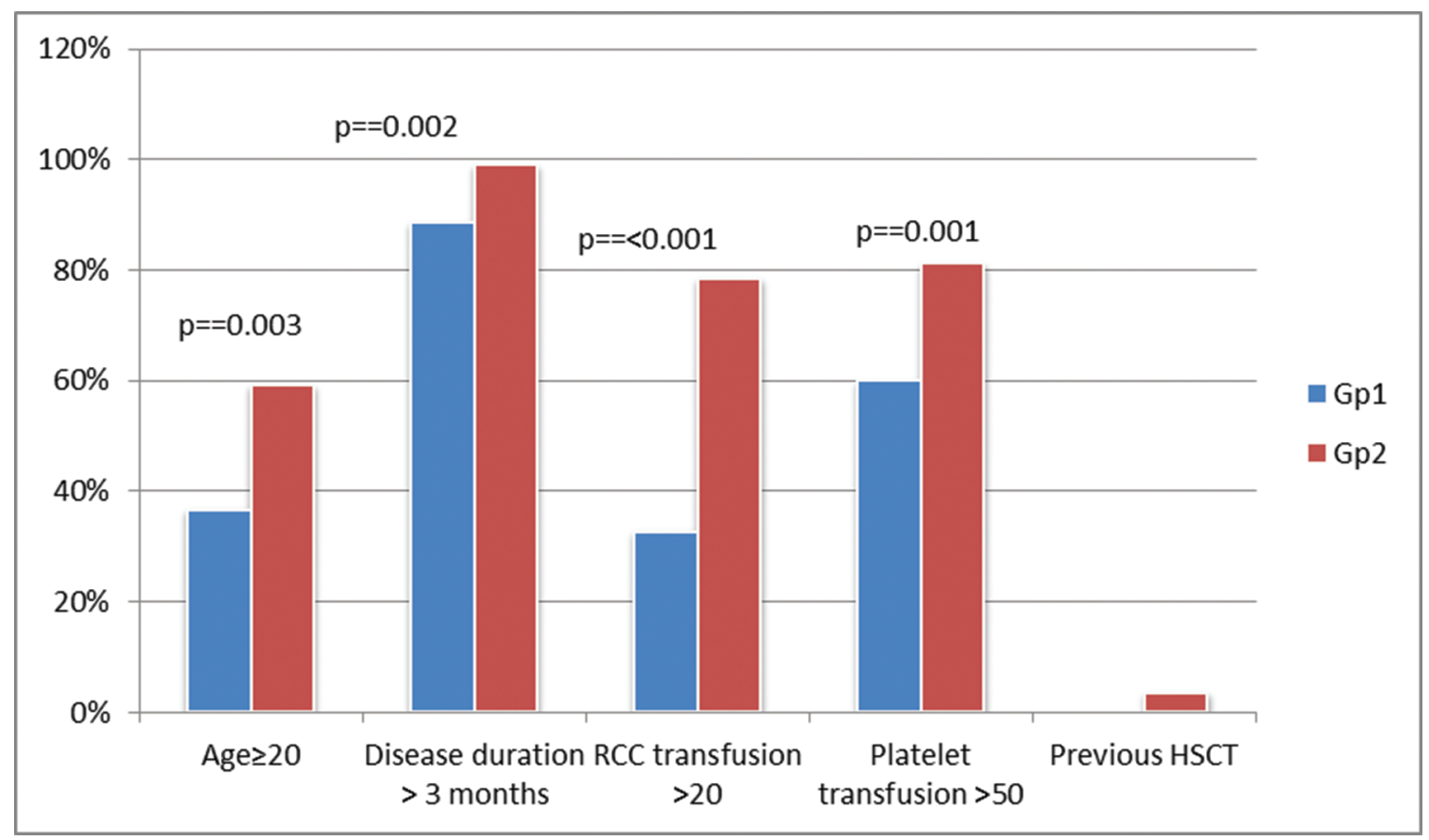

Figure 1 Comparison of the frequency of high-risk factors in patients receiving Gp1 and Gp2 conditioning. Patients in Gp2 had older age, prolonged disease duration prior to transplant, and had received higher number of RCC and platelet transfusions. 
$13(6.8 \%)$ patients. Transplant characteristics and engraftment details are summarized in Table 2.

\subsection{Transplant Complications}

Transplant complications in the study cohort are summarized in Table 3. Primary GF occurred in 8 (4.1\%) and secondary GF in 10 (5.2\%) patients. GF was more common in Gp1 (15.1\%) as compared to Gp2 (5.2\%) $p=0.03$. The majority of GF (86.3\%) occurred in patients with $>2$ risk factors $(p=0.02)$. The cumulative incidence of grade II-IV aGVHD was $8.1 \%$ (8.8\% in Gp1 and $7 \%$ in Gp2; $p=0.597$ ) for the difference. Thirty (15.6\%) patients developed cGVHD, limited in $13(6.7 \%)$ and extensive in 17

Table 2 Transplant characteristic of study population.

\begin{tabular}{|c|c|c|c|c|}
\hline Ser. No & $\begin{array}{l}\text { Transplant } \\
\text { Characteristics }\end{array}$ & $\begin{array}{c}\text { Gp1 } \\
\text { (Cy-ATG) } \\
\mathbf{n}=79\end{array}$ & $\begin{array}{c}\text { Gp2 (Flu- } \\
\text { Cy-ATG) } \\
\text { n }=113\end{array}$ & $p$ \\
\hline 1. & $\begin{array}{l}\text { Stem cell source } \\
\text { BM } \\
\text { BM + PBSC } \\
\text { PBSC }\end{array}$ & $\begin{array}{l}28(35.4 \%) \\
39(49.3 \%) \\
12(15.3 \%)\end{array}$ & $\begin{array}{c}69(61 \%) \\
43(38 \%) \\
1(1 \%)\end{array}$ & 0.316 \\
\hline 2. & $\begin{array}{l}\text { GVHD prophylaxis } \mathrm{n}(\%) \\
\text { Cyclosporine } \\
\text { Cyclosporine plus } \\
\text { methotrexate }\end{array}$ & $\begin{array}{l}32(40.5 \%) \\
47(59.5 \%)\end{array}$ & $\begin{array}{l}92(81.4 \%) \\
21(18.6 \%)\end{array}$ & $<.001$ \\
\hline 3. & $\begin{array}{l}\text { Nucleated Cell dose } \\
\left(10^{8} / \mathrm{kg}\right) \text { median } \\
\text { (range) }\end{array}$ & $\begin{array}{c}4.92 \\
(4.81-8.6)\end{array}$ & $\begin{array}{c}5.04 \\
(2.9-8.79)\end{array}$ & 0.599 \\
\hline 4. & $\begin{array}{l}\text { CD34 dose: }\left(10^{6} / \mathrm{kg}\right) \\
\text { median (range) }\end{array}$ & $\begin{array}{c}7.8 \\
(3.22-14.58)\end{array}$ & $\begin{array}{c}5.9 \\
(1.53-11.7)\end{array}$ & 0.034 \\
\hline 5. & $\begin{array}{l}\text { Neutrophil engraftment } \\
\text { days: median (range) }\end{array}$ & $12.5(9-20)$ & $13(10-19)$ & 0.282 \\
\hline 6. & $\begin{array}{l}\text { Platelet engraftment } \\
\text { days: median (range) }\end{array}$ & $21(14-34)$ & $23(14-43)$ & 0.923 \\
\hline 7. & $\begin{array}{l}\text { Major ABO mismatch; } \\
\mathrm{n}(\%)\end{array}$ & $18(22.7)$ & $25(22.3)$ & 0.53 \\
\hline 8. & $\begin{array}{l}\text { Gender mismatch donor } \\
\text {-recipient (female to } \\
\text { male); } \mathrm{n}(\%)\end{array}$ & $27(34.1)$ & $49(43.3)$ & 0.231 \\
\hline
\end{tabular}

BM: bone marrow; PBSC: peripheral blood stem cell; GVHD: graft versus host disease; TMA: thrombotic microangioapthy; CMV: cytomegalovirus.

Table 3 Comparison of transplant complications.

\begin{tabular}{|c|c|c|c|c|}
\hline Ser no & Complication n (\%) & Gp1 $(n=79)$ & $\begin{array}{c}\mathrm{Gp} 2(\mathrm{n}= \\
113)\end{array}$ & $p$ \\
\hline \multirow[t]{3}{*}{1.} & Graft failure & & & 0.03 \\
\hline & Primary & $4(5)$ & $4(3.5)$ & \\
\hline & Secondary & $8(10.1)$ & $2(1.7)$ & \\
\hline 2. & $\begin{array}{l}\text { Acute GVHD Grade } \\
\text { II-IV }\end{array}$ & $7(8.8)$ & $8(7)$ & 0.59 \\
\hline 3. & Chronic GVHD & $17(21.5)$ & $13(11.5)$ & 0.03 \\
\hline 4. & TMA & $2(2.5)$ & $7(6.1)$ & $<0.001$ \\
\hline 5. & $\begin{array}{l}\text { CMV reactivation (10 } \\
\text { evaluable patients in } \\
\text { Gp1 and } 41 \text { evaluable } \\
\text { patients in Gp2) }\end{array}$ & $4(40)$ & $14(34)$ & 0.23 \\
\hline 6. & $\begin{array}{l}\text { Tuberculosis } \\
\text { reactivation }\end{array}$ & $5(6.3)$ & $13(11.5)$ & 0.134 \\
\hline 7. & Serum sickness & $2(2.5)$ & $3(2.6)$ & 0.419 \\
\hline 8. & Erythrocytosis & $3(3.7)$ & $10(8.8)$ & 0.137 \\
\hline 9. & Hemorrhagic cystitis & $15(18.9)$ & $9(7.9)$ & 0.03 \\
\hline
\end{tabular}

GVHD: Graft versus host disease; TMA: thrombotic microangiopathy; CMV: cytomegalovirus.
(8.85\%). Chronic GVHD was more common in Gp1 $(p=0.03)$. There was no effect of the type of GVHD prophylaxis used (cyclosporine alone or cyclosporine plus MTX) on the frequency and severity of acute or chronic GVHD in the whole study cohort $(p=0.951)$ and between either group $(p=0.34)$. The type of GVHD prophylaxis had no significant effect on the outcome. OS in cyclosporine alone and cyclosporine plus MTX was $78.1 \%$ and $78.3 \%$ in $\mathrm{Gp} 1(p=0.163)$ and $85 \%$ and $83.7 \%$ in Gp2 $(p=0.671)$, respectively. Similarly, DFS was not different between the 2 groups $(p=0.391)$ (Figure 2).

Hemorrhagic cystitis (HC) was seen in $12.5 \%$ of patients. Patients receiving the $\mathrm{Gp} 1$ conditioning had a significantly higher frequency of $\mathrm{HC}(18.9 \%)$ as compared to Gp2 $(7.9 \%) p=0.03$. In patients with $\mathrm{HC}, \mathrm{BKV}$ reactivation was detected by PCR in four patients (2.7\%), being 3 in Gp1 and 1 in Gp2. Transplant-associated thrombotic microangiopathy (was more common in Gp2 $(p \leq 0.001)$. CMV reactivation was seen in 4 out of 10 patients in Gp1 (40\%) and 14 out of 41 evaluable patients in Gp2 (34\%). Reactivation of tuberculosis occurred in eighteen patients $(9.3 \%)$ and the risk was not different between the 2 groups $(p=0.134)$.

Erythrocytosis was an unusual complication seen in 13 patients $(6.7 \%)$, at a median of 12 months after transplant. Ten patients (8.8\%) belonged to Gp2 while 3 (3.7\%) belonged to Gp1 ( $p=0.137)$.

\section{SURVIVAL}

The median follow-up of entire study group was 36 (7-206) months, being 39 months (13-206) in Gp1 and 33 (7-165) in Gp2 $(p=0.391)$. The day-100 TRM was significantly higher in patients receiving the Gp1 (17.7\%), as compared to the Gp2 conditioning $(7.9 \% ; p=0.04)$. The OS of the study cohort was $81.3 \%$, DFS was $76.6 \%$ and GRFS was $64.1 \%$.

When patients were stratified into two groups, patients receiving $\mathrm{Gp} 2$ conditioning had a nonsignificant higher probability of OS as compared to Gp1 conditioning: $85.8 \%$ versus $77.2 \%(p=0.15)$, respectively. DFS and GRFS were significantly higher in Gp2 as compared to Gp1: DFS of $84.1 \%$ versus $68.4 \%(p=0.02)$, GRFS of $77.9 \%$ versus $54.4 \%(p=0.01)$, respectively (Figure 3 ).

The FLU-based conditioning was associated with a better outcome than that of to the conventional CY + ATG regimen, when compared for different stem cell sources. The OS among Gp1 (CY + ATG) and Gp2 (FLU-CY-ATG) was $78.6 \%$ versus $82.4 \%$ for $\mathrm{BMH}$, $74.4 \%$ versus $93 \%$ for $\mathrm{BMH}+\mathrm{PBSC}$ and $83.3 \%$ versus $100 \%$ in the case of PBSC (only 1 patient in Gp 2 received $\mathrm{PBSC}$ and is alive) ( $p=$ $0.054)$. The DFS in $\mathrm{Gp} 1$ versus $\mathrm{Gp} 2$ was $64.3 \%$ versus $79.4 \%$ (BMH), $71.8 \%$ versus $93 \%$ (BMH + PBSC) and $66.7 \%$ versus $100 \%$ for PBSC only $(p=0.006)$.

Overall, 36 patients died after transplantation, the most common cause of death being GF $(5.2 \% ; n=10)$ and infection $(5.2 ; n=10)$. Six patients died of primary and 4 of secondary GF. Causes of death per conditioning regimen are summarized in Table 4.

When data were split into three quartiles (2001-2008; 2009-2014; 2015-2019) patients transplanted with FLU-based conditioning had superior OS, DFS, GRFS in all quartiles after adjusting for covariates, indicating that the benefit of FLU remained consistent over long-time periods in high-risk patients. The majority of patients 

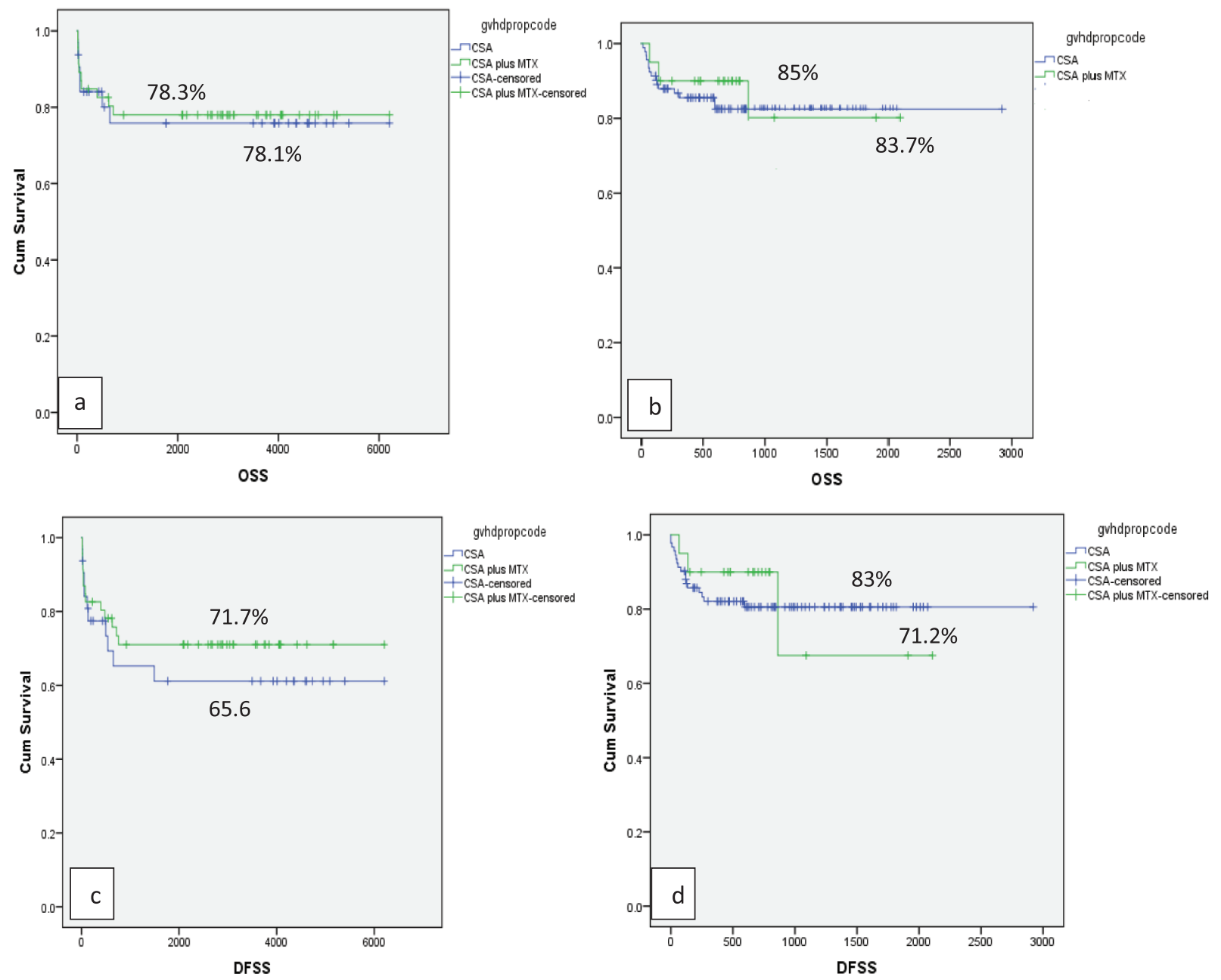

Figure 2 Effect of GVHD prophylaxis on OS and DFS (a) In Gp1: OS with Cyclosporine (blue line) alone and Cyclosporine plus MTX (green line) was 78.1\% and 78.3\% respectively with $p=0.163$ (b) In Gp2: OS with Cyclosporine alone (blue line) and Cyclosporine plus MTX (green line) was $85 \%$ and $83.7 \%$ respectively with $p=0.671$ (c) In Gp1: DFS 65.6\% in Cyclosporine alone (blue line) while $71.7 \%$ in Cyclosporine plus MTX (green line), $p=0.165$ (d) In Gp2: DFS 83\% in Cyclosporine alone (blue line) while $71.2 \%$ in Cyclosporine plus MTX (green line), $p=0.06$. OS: overall survival; DFS: disease-free survival; MTX: methotrexate; GRFS: graft versus host disease free relapse free survival.

(67\%) had $>2$ risk factors in our study; therefore, we investigated if the type of conditioning regimen influenced the survival in this individual cohort. The OS and DFS were significantly better in patients with $\leq 2$ risk factors ( $p \leq 0.001)$. The use of FLU-based conditioning led to better OS and DFS in patients with $>2$ risk factors as compared to the CY-ATG conditioning (Figure 4).

We performed a Cox regression analysis on OS, DFS and GRFS using patient age, transfusion of RCC and platelets, disease duration before transplant and conditioning regimen as associated factors. This analysis revealed that all 3 parameters remained significantly superior in the FLU-based conditioning regimen, even after correcting for all the above factors $(p=0.001)$.

\section{DISCUSSION}

MRD transplant is the treatment of choice for younger patients with severe and very severe AA. Being a nonmalignant disorder, the goal of transplantation in AA is to achieve long-term GRFS [18]. In Western countries, early diagnosis and transplantation, better supportive care, use of CY + ATG conditioning, BMH as stem cell source and use of cyclosporine plus MTX for GVHD prophylaxis has resulted in significant reduction in GF, GVHD, improvement in OS and GRFS [19,20], with documented engraftment rates of 95\% and OS nearing $90 \%$ [21].

On the contrary, the management of AA in developing countries is challenging. The prevalence of AA is higher as compared to the Western populations [22] and, yet, there is paucity of information regarding mutational profile and disease pathogenesis in this region [23]. Delay in diagnosis and referral, long waiting time before transplant, lack of finances, use of non-leuko-depleted blood products, family donations and recurrent infections pre-transplantation result in allo-immunization, GF, GVHD and increased risk of infectious and noninfectious complications. The presence of these risk factors leads to the inferior overall outcomes of conventional transplantation strategies in these high-risk patients [4,24,25]. 

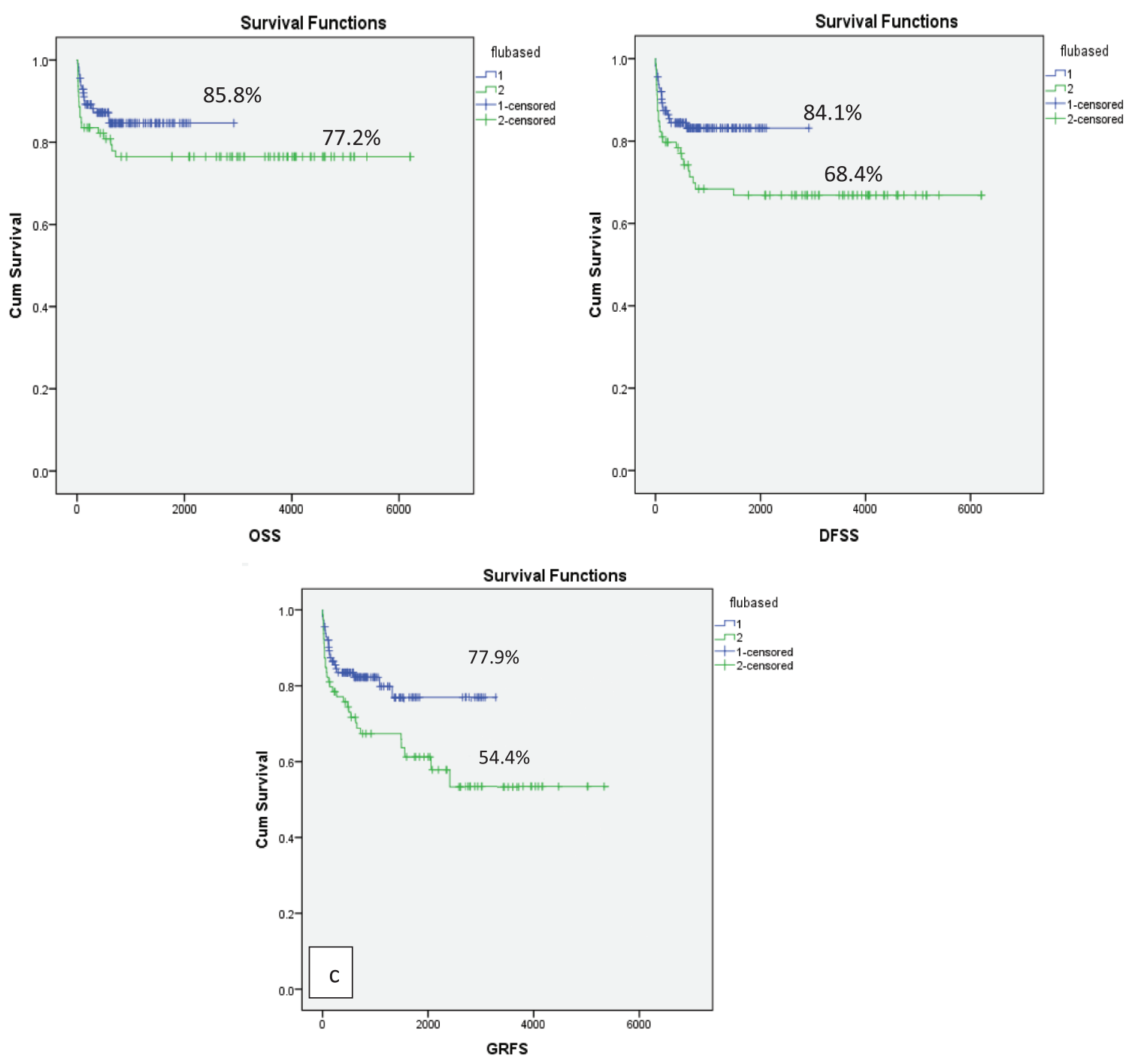

Figure 3 OS, DFS and GRFS as per conditioning regimen Gp1 and Gp2(a) OS of 77.2\% in Gp1 and 85.8\% in Gp2, $p=0.15$ (b) DFS of $68.4 \%$ in Gp1 and $84.1 \%$ in Gp2 ( $p=0.02$ ) (c) GRFS of $54.4 \%$ in Gp1 and 77.9\% in Gp2, $p=0.01$. OS: Overall survival; Flu: Fludarabine; Gp: group; GRFS: graft versus host disease relapse-free survival.

Table 4 Cause of death.

\begin{tabular}{lllc}
\hline Ser no & Complication n (\%) & Gp1 & Gp2 \\
\hline 1. & Graft failure & & \\
& $\quad$ Primary & $3(3.7)$ & $3(3.5)$ \\
& Secondary & $7(8.8)$ & $1(0.7)$ \\
3. & GVHD & $2(2.5)$ & $2(2.5)$ \\
4. & TMA & $1(1.2)$ & $4(3.5)$ \\
5. & Infection & $6(7.5)$ & $4(3.5)$ \\
6. & Secondary malignancy & $1(1.2)$ & - \\
7. & Hepatic failure & $1(1.2)$ & $1(0.8)$ \\
8. & Bleeding & $1(1.2)$ & $2(2.5)$ \\
9. & TRALI & $1(1.2)$ & - \\
\hline
\end{tabular}

GVHD: Graft versus host disease; TMA: thrombotic microangiopathy; CMV: cytomegalovirus.

The CIBMTR data on HLA-matched HSCT for severe AA showed a 5 -year survival of $85 \%$ for patients $<20$ years and $64 \%$ for those $>20$ years using CY-ATG conditioning and PBSC harvest [26]. The EBMT data on 1,275 patients identified age $\geq 20$ years, time from diagnosis to transplant $>114$ days, absence of ATG in conditioning and use of conditioning other than CY200 mg/ $\mathrm{kg}$ as negative predictors of survival, with an OS of $64 \%$ in patients with 3-4 negative predictors [4]. Saunders et al. reported that rejection rates among patients with or without prior transfusion were $22 \%$ and $10 \%$, respectively [27]. Data from Japanese, Indian and Mexican studies suggested that $>20$ transfusions prior to transplantation were independently associated with high rates of GF, even after incorporation of ATG in the conditioning [6,28,29]. Lee et al. documented that higher pre-transplant transfusion (>32 RCC) is associated with increased TRM and reduced OS [3].

Different conditioning regimens were employed over the last 2 decades in an attempt to reduce GF, GVHD, TRM and improve outcome in these high-risk patients. However, most studies have remained limited to case series or single institutional data with limited number of patients and lack of consensus definition for highrisk $\mathrm{AA}[6,10,28,30]$.

FLU is a purine analog with potent immunosuppressive and lympho-depleting properties. When used in combination with 

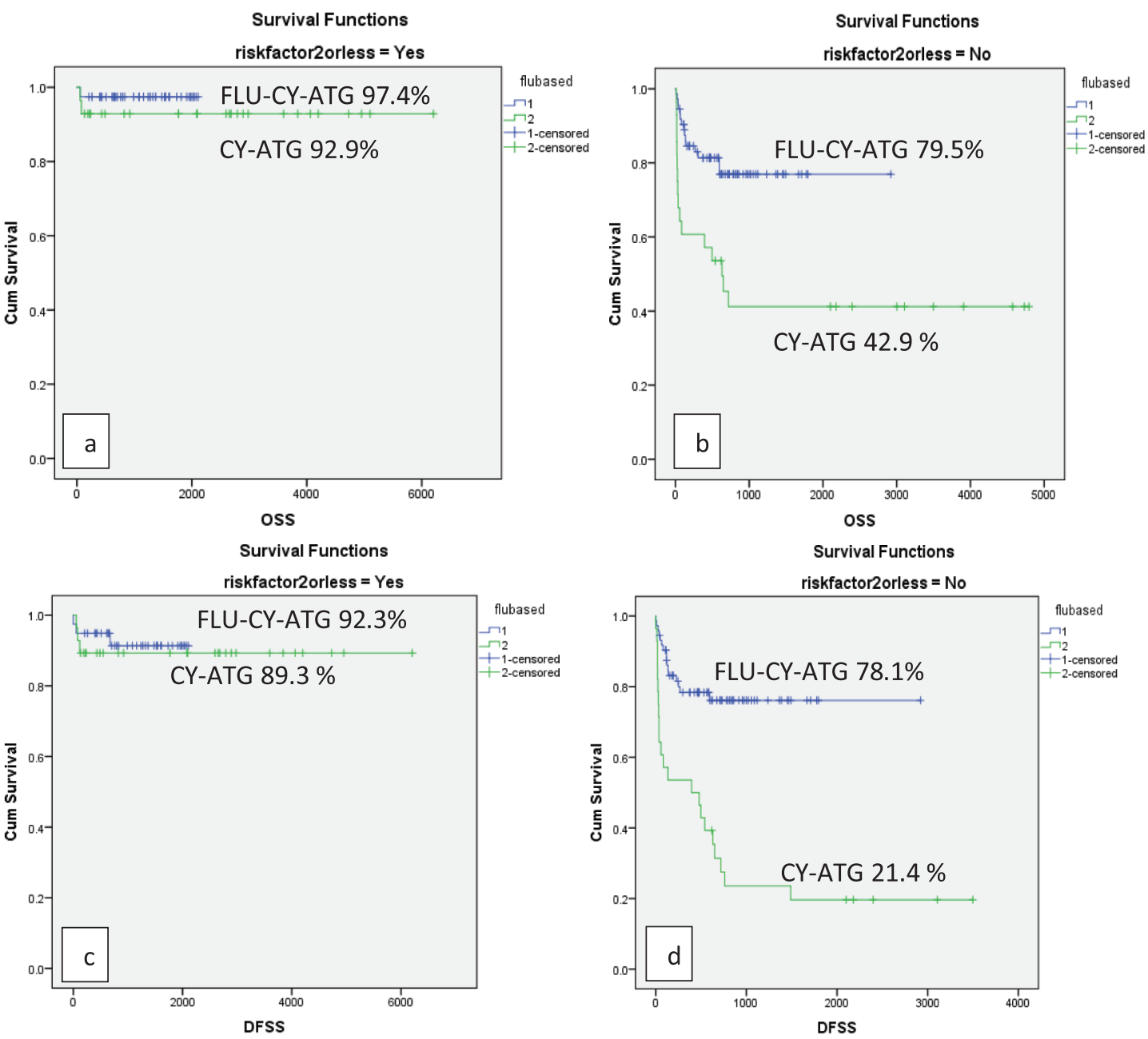

Figure 4 OS and DFS as per number of high-risk features in Gp1 and Gp2(a) OS of $92.9 \%$ in patients with $\leq 2$ risk factors in Gp1 and $97.4 \%$ in Gp2 ( $p=0.002)$ (b) OS of $42.9 \%$ in patients with $>2$ risk factors in Gp1 and 79.5\% in Gp2 ( $p \leq 0.001)$ (c) DFS of $89.3 \%$ in patients with $\leq 2$ risk factors in Gp1 and $92.3 \%$ in Gp2 $(p \leq 0.001)$ (d) DFS of $21.4 \%$ in patients with $>2$ risk factors in $\mathrm{Gp} 1$ and $78.1 \%$ in Gp2 $(p \leq 0.001)$.

CY, it works synergistically by inhibiting alkylation-induced DNA repair. It is well tolerated at older ages, has low cost and has proven to be beneficial in reducing GF in high-risk AA patients [30]. The toxicities of $\mathrm{CY}$ at the doses used in CY-ATG conditioning regimens are substantial, especially in high-risk patients who are already alloimmunized and have a longer duration of illness, with recurrent infections. Using FLU-CY-ATG conditioning allows a reduction in doses of CY without compromising the success of engraftment and, at the same time, reducing toxicities. Retrospective data from EBMT also suggested favorable outcomes with FLU-based regimens in older patients [7]. Early studies reported inferior OS in transfused patients as compared to those untransfused, due to graft rejection [31].

A retrospective analysis from three Indian Centers documented GF of 3.3\% using FLU-based conditioning. However, the study included both high-risk and non-high-risk cases [32]. GF in our study was $9.7 \%$, being higher in patients receiving CY-ATG (15.1\%) as compared to those treated with FLU-CY-ATG (5.2\%). These results are lower than the rates previously reported with CY-ATG [33]. In our study, the use of FLU-based conditioning was associated with low toxicity and 100-day mortality, as compared to the CY-ATG group (7.9\% versus $17.7 \%), p=0.04$. Similar results were documented by George et al. [32]. A randomized trial comparing FLU-CY-ATG with CY-ATG in severe AA and hypoplastic myelodysplastic syndrome (MDS) documented GF rates of $13.4 \%$ versus $16.8 \%$, respectively and OS of $(85.6 \%$ versus $77.7 \% ; p=0.407)$. That study, however, did not report on DFS and GRFS, included fewer patients, included alternative donor transplants and patients with hypoplastic MDS. Nonetheless, results with FLU-CY-ATG showed a nonsignificant OS and lesser regimen-related toxicities [34]. In our study, OS and DFS were significantly better in patients with $\leq 2$ risk factors as compared to those with $>2$ risk factors $(p \leq 0.001)$. In the latter group, the OS $(76.7 \%)$ and DFS (75.3\%) were significantly better in patients receiving FLU-based conditioning as compared to OS (42.9\%) and DFS (21.4\%) in those receiving CY + ATG ( $p \leq 0.001)$, thus emphasizing that for patients with increased number of risk factors, FLU-CY-ATG remains the optimal choice.

In our study, PBSC was more used in Gp1 patients, because these were transplanted between 2002 and 2006, when there was a trend 
to use PBSC to facilitate early engraftment and reduce infectionrelated complications [35]. Previous studies had shown that the use of PBSC reduces the risk of graft rejection in multiply transfused patients [36]. Many centers in developing countries continue to use PBSC as the preferred graft source in AA, because the early and sustained engraftment achieved with these stem cells helps to salvage patients with ongoing infection, and reduces graft rejection [32].

Cyclosporine alone was used for GVHD prophylaxis in 124 (64.5\%) and cyclosporine plus MTX in 68 (35.4\%) cases. The latter combination was used more frequently in patients receiving the Gp1 conditioning CY-ATG (59.5\%) as compared to $18.6 \%$ in Gp2 ( $p \leq$ $0.001)$. Patients in Gp2 were older, highly immunized, had a longer duration of disease and were at a higher risk of GVHD as compared to Gp2. However, the use of cyclosporine plus MTX was not superior to cyclosporine alone in preventing acute or chronic GVHD $(p=0.951)$. The type of GVHD prophylaxis had no significant effect on improving OS or GRFS. This may be due to the mucosal injury caused by MTX, leading to increased expression of damageassociated molecular patterns (DAMP), which are a known trigger for GVHD [37,38]. More studies are needed to validate this finding, and the use of FLU was not associated with increased infectious complications. George et al. reported the usefulness of FLU-Cy conditioning in patients with fungal infections, documenting an OS of $61.2 \%[39]$.

We acknowledge that there are a few limitations to the study. It was a retrospective analysis and patients were not randomized. The FLUbased regimen was used for high-risk patients, who were older, heavily transfused and had a longer duration of disease. Despite these biases, patients with Gp2 conditioning had better OS, DFS and GRFS, indicating that the survival could have been better in Gp2 if a more homogenous patient selection was done. The study by Qamar et al. [8] and the current one provide further evidence that FLU-based conditioning provides favorable outcomes in high-risk AA patients undergoing MRD. Furthermore, the AFBMTC defined high-risk criteria that can be used to develop risk adopted approach for selection of conditioning regimens in AA patients.

\section{CONCLUSION}

FLU-based conditioning is better tolerated with lower TRM and is associated with lower rates of rejection, better OS, DFS and GRFS as compared to conventional CY-based conditioning. The survival benefit is more pronounced in patients with more than 2 risk factors. Bone marrow as a source of stem cells and cyclosporine alone as GVHD prophylaxis are the preferable options. A randomized control trial of FLU-based versus conventional CY-containing conditioning would be helpful in establishing a standard of care regimen in high-risk AA patients.

\section{CONFLICT OF INTEREST}

This manuscript contains original research not previously published or submitted for publication elsewhere while under consideration. The authors declare no conflict of interest with this manuscript.

\section{Funding Statement}

The authors have no financial conflict with the subject matter or materials discussed in the manuscript.

\section{AUTHORS' CONTRIBUTIONS}

IR, CQN and AP designed the study and contributed equally to this article. All authors contributed to data collection, analysis, literature review and reference citation.

\section{REFERENCES}

[1] Sureda, A, Bader, P, Cesaro, S, Dreger, P, Duarte, RF, Dufour, C, et al. Indications for allo- and auto-SCT for haematological diseases, solid tumours, and immune disorders: current practice in Europe, 2015. Bone Marrow Transplant 2015;50;1037-56.

[2] Bacigalupo, A, Socié, G, Schrezenmeier, H, Tichelli, A, Locasciulli, A, Fuehrer, M, et al. Bone marrow versus peripheral blood as the stem cell source for sibling transplants in acquired aplastic anemia: survival advantage for bone marrow in all age groups. Haematologica 2012;97;1142-8.

[3] Lee, S, Yahng, S, Cho, B, Eom, K, Kim, Y, Kim, H, et al. Impact of pretransplant red cell transfusion on outcome after allogeneic stem cell transplantation in adult patients with severe aplastic anemia. Bone Marrow Transplant 2016;51;1323.

[4] Locasciulli, A, Oneto, R, Bacigalupo, A, Socié, G, Korthof, E, Bekassy, A, et al. Outcome of patients with acquired aplastic anemia given first line bone marrow transplantation or immunosuppressive treatment in the last decade: a report from the European Group for Blood and Marrow Transplantation. Haematologica 2007;92;11-18.

[5] Maury, S, Bacigalupo, A, Anderlini, P, Aljurf, M, Marsh, J, Socié, G, et al. Improved outcome of patients older than 30 years receiving HLA-identical sibling hematopoietic stem cell transplantation for severe acquired aplastic anemia using fludarabine-based conditioning: a comparison with conventional conditioning regimen. Haematologica 2009;94;1312-15.

[6] George, B, Mathews, V, Viswabandya, A, Kavitha, M, Srivastava, A, Chandy, M. Fludarabine and cyclophosphamide based Reduced Intensity Conditioning (RIC) regimens reduce rejection and improve outcome in Indian patients undergoing allogeneic stem cell transplantation for severe aplastic anemia. Bone Marrow Transplant 2007;40;13.

[7] Al-Zahrani, H, Nassar, A, Al-Mohareb, F, Al-Sharif, F, Mohamed, S, Al-Anazi, K, et al. Fludarabine-based conditioning chemotherapy for allogeneic hematopoietic stem cell transplantation in acquired severe aplastic anemia. Biol Blood Marrow Transplant 2011;17;717-22.

[8] Iftikhar, R, Satti, TM, Mahmood, SK, Ghafoor, T, Shamshad, GU, Shahbaz, N, et al. Outcome of fludarabine based conditioning in high risk aplastic anemia patients undergoing matched related donor transplantation: a single center study from Pakistan. Biol Blood Marrow Transplant 2019;25;2375-82.

[9] Srinivasan, R, Takahashi, Y, Philip McCoy, J, Espinoza-Delgado, I, Dorrance, C, Igarashi, T, et al. Overcoming graft rejection in heavily transfused and allo-immunised 
patients with bone marrow failure syndromes using fludarabine-based haematopoietic cell transplantation. Br J Haematol 2006;133;305-14.

[10] Resnick, IB, Aker, M, Shapira, MY, Tsirigotis, PD, Bitan, M, Abdul-Hai, A, et al. Allogeneic stem cell transplantation for severe acquired aplastic anaemia using a fludarabine-based preparative regimen. Br J Haematol 2006;133;649-54.

[11] Camitta, BM, Rappeport, JM, Parkman, R, Nathan, DG. Selection of patients for bone marrow transplantation in severe aplastic anemia. Blood 1975;45;355-63.

[12] Bacigalupo, A, Hows, J, Gluckman, E, Nissen, C, Marsh, J, Van Lint, MT, et al. Bone Marrow Transplantation (BMT) versus immunosuppression for the treatment of Severe Aplastic Anaemia (SAA): a report of the EBMT SAA working party. Br J Haematol $1988 ; 70 ; 177-82$

[13] Alter, BP. Inherited bone marrow failure syndromes: considerations pre- and posttransplant. Hematol Am Soc Hematol Educ Prog 2017;2017;88-95.

[14] Hicheri, Y, Einsele, H, Martino, R, Cesaro, S, Ljungman, P, Cordonnier, C. Environmental prevention of infection in stem cell transplant recipients: a survey of the Infectious Diseases Working Party of the European Group for Blood and Marrow Transplantation. Transplant Infect Dis 2013;15;251-8.

[15] Shamsi, T, Hashmi, K, Adil, S, Ahmad, P, Irfan, M, Raza, S, et al. The stem cell transplant program in Pakistan-the first decade. Bone Marrow Transplant 2008;42;S114-S7.

[16] Dignan, FL, Clark, A, Amrolia, P, Cornish, J, Jackson, G, Mahendra, $\mathrm{P}$, et al. Diagnosis and management of acute graft-versus-host disease. Br J Haematol 2012;158;30-45.

[17] Vigorito, AC, Campregher, PV, Storer, BE, Carpenter, PA, Moravec, CK, Kiem, H-P, et al. Evaluation of NIH consensus criteria for classification of late acute and chronic GVHD. Blood 2009;114;702-8.

[18] Devillier, R, Labussière-Wallet, H, Clément, L, Yakoubagha, I, Bay, J-O, Gandemer, V, et al. A composite event-free survival end point to evaluate outcome after allogeneic transplantation for severe aplastic anemia: a study on behalf of the francophone society of bone marrow transplantation and cellular therapy (SFGMTC). Am Soc Hematology 2016;128;2674.

[19] Socié, G. Allogeneic BM transplantation for the treatment of aplastic anemia: current results and expanding donor possibilities. ASH Educ Prog Book 2013;2013;82-6.

[20] Bacigalupo, A, Socié, G, Hamladji, RM, Aljurf, M, Maschan, A, Kyrcz-Krzemien, S, et al. Current outcome of HLA identical sibling versus unrelated donor transplants in severe aplastic anemia: an EBMT analysis. Haematologica 2015;100;696-702.

[21] Scheinberg, P, Young, NS. How I treat acquired aplastic anemia. Blood 2012;120;1185-96.

[22] Kojima, S. Why is the incidence of aplastic anemia higher in Asia? Expert Rev Hematol 2017;10;277-9.

[23] Taj, M, Shah, T, Aslam, SK, Zaheer, S, Nawab, F, Shaheen, S, et al. Environmental determinants of aplastic anemia in Pakistan: a case-control study. J Public Health 2016;24;453-60.

[24] Champlin, RE, Horowitz, MM, van Bekkum, DW, Camitta, BM, Elfenbein, GE, Gale, RP, et al. Graft failure following bone marrow transplantation for severe aplastic anemia: risk factors and treatment results. Blood 1989;73;606-13.

[25] Koh, L, Koh, M, Ng, H, Hwang, W, Goh, Y, Linn, Y, et al. Allogeneic hematopoietic stem cell transplantation for patients with severe aplastic anemia following nonmyeloablative conditioning using 200-cGy total body irradiation and fludarabine. Biol Blood Marrow Transplant 2006;12;887-90.

[26] Schrezenmeier, H, Passweg, JR, Marsh, JC, Bacigalupo, A, Bredeson, CN, Bullorsky, E, et al. Worse outcome and more chronic GVHD with peripheral blood progenitor cells than bone marrow in HLA-matched sibling donor transplants for young patients with severe acquired aplastic anemia. Blood 2007; 110;1397-400.

[27] Sanders, JE, Storb, R, Anasetti, C, Deeg, H, Doney, K, Sullivan, KM, et al. Marrow transplant experience for children with severe aplastic anemia. Am J Pediatr Hematol Oncol 1994; 16;43-9.

[28] Kumar, R, Prem, S, Mahapatra, M, Seth, T, Chowdhary, D, Mishra, P, et al. Fludarabine, cyclophosphamide and horse antithymocyte globulin conditioning regimen for allogeneic peripheral blood stem cell transplantation performed in nonHEPA filter rooms for multiply transfused patients with severe aplastic anemia. Bone Marrow Transplant 2006;37;745.

[29] Kobayashi, R, Yabe, H, Hara, J, Morimoto, A, Tsuchida, M, Mugishima, $\mathrm{H}$, et al. Preceding immunosuppressive therapy with antithymocyte globulin and ciclosporin increases the incidence of graft rejection in children with aplastic anaemia who underwent allogeneic bone marrow transplantation from HLA-identical siblings. Br J Haematol 2006;135;693-6.

[30] Gómez-Almaguer, D, Vela-Ojeda, J, Jaime-Pérez, JC, Gutiérrez-Aguirre, CH, Cantú-Rodríguez, OG, Sobrevilla-Calvo, $\mathrm{P}$, et al. Allografting in patients with severe, refractory aplastic anemia using peripheral blood stem cells and a fludarabine-based conditioning regimen: the Mexican experience. Am J Hematol 2006;81;157-61.

[31] Storb, R, Thomas, ED, Buckner, CD, Clift, RA, Deeg, HJ, Fefer, A, et al. Marrow transplantation in thirty untransfused patients with severe aplastic anemia. Ann Intern Med 1980;92;30-6.

[32] George, B, Mathews, V, Lakshmi, KM, Melinkeri, S, Sharma, A, Viswabandya, A, et al. The use of a fludarabine-based conditioning regimen in patients with severe aplastic anemia-a retrospective analysis from three I ndian centers. Clin Transplant 2013;27;923-9.

[33] Champlin, RE, Perez, WS, Passweg, JR, Klein, JP, Camitta, BM, Gluckman, E, et al. Bone marrow transplantation for severe aplastic anemia: a randomized controlled study of conditioning regimens. Blood 2007;109;4582-5.

[34] Kim, H, Lee, J-H, Joo, Y-D, Bae, SH, Hyun, MS, Lee, J-H, et al. A randomized comparison of cyclophosphamide vs. reduced dose cyclophosphamide plus fludarabine for allogeneic hematopoietic cell transplantation in patients with aplastic anemia and hypoplastic myelodysplastic syndrome. Ann Hematol 2012;91;1459-69.

[35] Min, CK, Kim, DW, Lee, JW, Han, CW, Min, WS, Kim, CC. Supplemental peripheral blood stem cells to decrease marrow rejection in adult patients with severe aplastic anemia. Am J Hematol 2002;69;15-22.

[36] Min, C-K, Kim, DW, Lee, JW, Han, CW, Min, WS, Kim, CC. Hematopoietic stem cell transplantation for high-risk adult patients with severe aplastic anemia; reduction of graft failure by enhancing stem cell dose. Haematologica 2001;86;303-10.

[37] Markey, KA, MacDonald, KP, Hill, GR. The biology of graftversus-host disease: experimental systems instructing clinical practice. Blood 2014;124;354-62. 
[38] Cooke, KR, Luznik, L, Sarantopoulos, S, Hakim, FT, Jagasia, M, Fowler, DH, et al. The biology of chronic graft-versus-host disease: a task force report from the National Institutes of Health Consensus Development Project on Criteria for Clinical Trials in Chronic Graft-versus-Host Disease. Biol Blood Marrow Transplant 2017;23;211-34.
[39] George, B, Mathews, V, Viswabandya, A, Srivastava, A, Chandy, M. Fludarabine-based reduced intensity conditioning regimens for allogeneic hematopoietic stem cell transplantation in patients with aplastic anemia and fungal infections. Clin Transplant 2009;23;228-32. 